\title{
Katanin P60: a potential biomarker for lymph node metastasis and prognosis for non-small cell lung cancer
}

\author{
Lei Wang ${ }^{1,2 \dagger}$, Jicheng Tantai ${ }^{3 \dagger}$ and Xiaoli Zhu ${ }^{1 *}$ (D)
}

\begin{abstract}
Background: This study aimed to assess the correlation of katanin P60 expression with clinical characteristics and survival profiles of surgical non-small cell lung cancer (NSCLC) patients.

Methods: Two hundred and sixty-five primary NSCLC patients treated by surgical resection were retrospectively viewed. The expression of katanin P60 in the tumor specimen was detected by the immunohistochemical (IHC) staining assay. Preoperative clinical data were collected from patients' medical records, and survival data were extracted from follow-up records.

Results: There were 127 (47.9\%) and 138 (52.1\%) patients with katanin P60-low expression and -high expression, respectively; in addition, patients presenting katanin P60-hight, -high++, and -high+++ expression were 62 (23.4\%), 63 (23.8\%), and 13 (4.9\%), respectively. Katanin P60 expression was correlated with lymph node (LYN) metastasis and advanced TNM stage but not pathological grade, tumor size, carcinoembryonic antigen (CEA) level or other non-tumor features in NSCLC patients. Regarding survival profiles, disease-free survival (DFS) and overall survival (OS) were both the lowest in katanin P60-high+++ expression patients, followed with katanin P60-high++ patients, katanin P60-high+ patients, and the highest in katanin P60-low expression patients. Further analysis illustrated that katanin P60-high expression was an independent predictive factor for unfavorable DFS and OS in NSCLC patients.

Conclusions: Katanin P60 presents potential as a biomarker for lymph node metastasis and prognosis in NSCLC patients.
\end{abstract}

Keywords: Katanin P60, Lymph node metastasis, Survival, Tumor progression, Non-small cell lung cancer

\section{Background}

Lung cancer is the most commonly diagnosed malignancy as well as the leading cause of cancer-related deaths worldwide, among which non-small cell lung cancer (NSCLC) represents $85 \%$ of all lung cancer cases [1]. Although early screening has been widely applied, over a half of NSCLC patients are still diagnosed as advanced stage, leaving a limited window of curative treatments

\footnotetext{
* Correspondence: zhuxiaoli90@163.com

${ }^{+}$Lei Wang and Jicheng Tantai contributed equally to this work.

'Department of Interventional Radiology, The First Affiliated Hospital of Soochow University, 899 Pinghai Road, Suzhou 215006, China

Full list of author information is available at the end of the article
}

and bringing challenge to disease management [2]. Molecular biomarkers have been investigated in NSCLC to guide treatment strategy and develop treatment agents, from which, the establishment of novel therapeutic drugs have emerged [3]. The new targeted therapies, immune therapies, or alterations have shown improved survival profiles during the recent years, while the general prognosis of NSCLC is still unsatisfactory. Therefore, in order to achieve a long-term durable response and survival of NSCLC patients, it is fundamental to constantly investigate in biomarker-directed regimens and therapies. 
Katanin, belonging to the family of microtubule severing enzymes, is a heterodimer with AAA catalytic subunit katanin P60 and non-AAA subunit katanin P80 [4]. Previous studies mostly focus on the role of katanin in mitosis, meiosis, and microtubule release from centrosome in the neuron, whereas only a few of them investigate the implication of katanin in malignancies [5-8]. One existing study indicates that katanin P80 correlates with larger tumor size, lymph node (LYN) metastasis, and advanced TNM stage and serves as a potential biomarker for predicting poor survival in NSCLC patients [9]. As for katanin P60, it is initially identified to be aberrantly expressed in prostate cancer patients with bone metastasis, and upregulation of katanin P60 inhibits cell proliferation but enhances cell migration [10]. In breast cancer, katanin P60 promotes cell migration, and high katanin P60 expression in tumor tissue is correlated with lymph node metastasis as well as poor overall survival (OS) in breast cancer patients [11]. As for NSCLC, only a single glimpse of study reports the regulatory role of katanin P60 in microtubule fragmentation in NSCLC cells, whereas the clinical implication of katanin P60 is poorly characterized [12]. In this study, we aimed to assess the correlation of katanin P60 with clinical characteristics and survival profiles in surgical NSCLC patients.

\section{Methods}

\section{Patients}

Two hundred and sixty-five primary NSCLC patients treated by surgical resection in our hospital between January 2012 and December 2014 were retrospectively analyzed in this study. The eligible subjects were (1) histopathologically confirmed as primary NSCLC, (2) TNM stage I-IIIA, (3) age $\geq$ 18 years, (4) underwent surgical resection, (5) tumor tissue specimens derived from resection were accessible and available for immunohistochemical (IHC) staining assay, (6) preoperative clinical features and follow-up data were complete and available, (7) no neoadjuvant therapy before surgery, (8) not relapsed NSCLC before surgery, and (9) no history of other malignancies. Approval for this study was obtained from Ethics Committee of The First Affiliated Hospital of Soochow University. The written informed consents were acquired from the patients or their family members.

\section{Tumor sample and clinical data collection}

All tumor specimens were formalin-fixed and paraffinembedded, which were obtained from the Pathology Department of our hospital. The expression of katanin P60 in the tumor specimen was detected by the IHC staining. In addition, preoperative clinical data including age, sex, history of smoke, history of drink, commonly chronic complications (hypertension, hyperlipidemia, diabetes, etc.), pathological grade, tumor size, LYN status, TNM stage, and carcinoembryonic antigen (CEA) level were collected from patients' medical records. Survival data were extracted from follow-up records (to date of 2018 December 31) to evaluate the disease-free survival (DFS) and OS.

\section{IHC staining}

Totally, 265 NSCLC samples were used for IHC staining of katanin P60. In brief, the rabbit anti-p60 katanin antibody (Abcam, USA) at 1:20 dilution and goat anti-rabbit IgG H\&L (HRP) (Abcam, USA) at 1:50,000 dilution were used as primary antibody and secondary antibody, respectively, in the IHC staining. All IHC procedures were performed as described in a previous study [13]. Finally, the expression of katanin P60 in tissue specimen was assessed by IHC score, which was obtained using a semi-quantitative scoring method as previously described [14]. The total IHC score was ranging from 0 to 12. Katanin P60-high expression was defined as the IHC score $>3$ in tumor slide, and katanin P60-low expression was defined as IHC score $\leq 3$ in tumor slide. Additionally, katanin P60-high expression was further classified as high+ (IHC score 4-6), high++ (IHC score 7-9), and high+++ (IHC score 10-12) [15]. In addition, we detected 40 out of 265 NSCLC tissues for the expression of katanin P80. The detailed procedure of katanin P80 detection was identical to that of katanin P60, while the antibodies used were (primary antibody, rabbit anti-p80 katanin antibody at 1:1000 dilution (Abcam, UK); secondary antibody, goat anti-rabbit IgG H\&L (HRP) (Abcam, USA) at 1:50,000 dilution).

\section{Real-time quantitative polymerase chain reaction (RT- qPCR)}

For further validation, we acquired the frozen-fresh NSCLC samples $(n=40)$ that were still available in the storage to detect the katanin P60 mRNA expression using RT-qPCR. The total RNA was extracted from frozen samples by RNeasy Protect Mini Kit (Qiagen, German) following the manufacturer's instruction and then reversely transcribed into cDNA using RT-PCR Quick Master Mix (Toyobo, Japan). Following was the fluorescent quantification using $\mathrm{SYBR}^{\ominus}$ Green Realtime PCR Master Mix (Toyobo, Japan) in ABI 7900HT Real-Time PCR System 7900 (Applied Biosystems, USA). GAPDH was used as an internal reference and katanin P60 mRNA expression was calculated by the method of $2^{-\Delta \Delta \mathrm{Ct}}$. The primers used was katanin P60, forward primer $\left(5^{\prime}-3^{\prime}\right)$ : TGGTTCAGATGGATGGTGTTGGA; reverse primer $\left(5^{\prime}-3^{\prime}\right)$ : TTCTCAAGGCGTCGTCTT AAAGC; GAPDH, forward primer $\left(5^{\prime}-3^{\prime}\right)$ : GACCACAG TCCATGCCATCAC; reverse primer $\left(5^{\prime}-3^{\prime}\right)$ : ACGCCT GCTTCACCACCTT. 


\section{Statistical analysis}

Statistical analysis was carried out using SPSS 24.0 software (IBM, USA), and figure plotting was performed using GraphPad Prism 6.01 software (GraphPad Software, USA). Clinical features were described as mean and standard deviation (SD), median and interquartile (IQR), or number (percentage). Comparison of clinical features between katanin P60-high patients and katanin P60-low expression patients was determined by chi-square test or Wilcoxon rank sum test. The DFS was calculated from the date of resection to the date of disease relapse, disease progression, or death. And OS was calculated from the date of resection to the date of death. DFS and OS were analyzed using KaplanMeier (K-M) method. Comparison of DFS and OS between or among groups was determined by Log-rank test. Factors related to DFS and OS were analyzed by univariate and forward stepwise multivariate Cox's proportional hazard regression model. $P$ value $<0.05$ was considered significant.

\section{Results}

\section{Baseline characteristics}

The mean age of NSCLC patients in this study was $62.0 \pm$ 10.6 years, and the median age was $62.0(55.0-68.0)$ years (Table 1). The gender composition was 205 (77.4\%) males and $60(22.6 \%)$ females. There were 150 (56.6\%), 103 (38.9\%), 95 (35.8\%), 87 (32.8\%), and $44(16.6 \%)$ patients with a history of smoke, history of drink, hypertension, hyperlipidemia, and diabetes, respectively. As for the tumor features, the number of patients at pathological grade G1, G2, and G3 were 44 (16.6\%), 160 (60.4\%), and 61 (23.0\%), respectively; the mean and median tumor size were $5.3 \pm 2.1 \mathrm{~cm}$ and $5.0(4.0-7.0)$ cm; 93 (35.1\%) patients occurred LYN metastasis and patients at TNM stage I, II, and III were 86 (32.5\%), 90 (34.0\%), and 89 (33.5\%), respectively. The mean and median CEA level was $47.7 \pm 172.8 \mathrm{ng} / \mathrm{mL}$ and $6.2(2.9-27.6) \mathrm{ng} / \mathrm{mL}$, respectively.

\section{Katanin P60 expression in NSCLC patients}

The expression of katanin P60 in NSCLC tissue was detected by $\mathrm{IHC}$ and categorized as katanin P60-low expression and katanin P60-high expression (which was further divided into high+, high++, and high+++ expression). The representative IHC images were presented in Fig. 1a. The number of patients with katanin P60-low expression and high expression were 127 (47.9\%) and 138 (52.1\%), respectively; in addition, patients with katanin P60-high+, -high++, and -high+++ expression were 62 (23.4\%), 63 (23.8\%), and 13 (4.9\%), respectively (Fig. 1b).

\section{Correlation of katanin P60 and clinical features in NSCLC patients}

The number of patients with pathological grade G1, G2, and G3 were 21 (16.5\%), 81 (63.8\%), and $25(19.7 \%)$ in katanin P60-low patients and 23 (16.7\%), 79 (57.2\%), and 36 (26.1\%) in katanin P60-high patients; analysis showed no association between katanin P60 expression and pathological grade $(P=0.399)$ (Fig. 2a). Besides, 81
Table 1 Characteristics of NSCLC patients

\begin{tabular}{ll}
\hline Items & NSCLC patients $(N=265)$ \\
\hline Age (years) & $62.0 \pm 10.6$ \\
Mean \pm SD & $62.0(55.0-68.0)$ \\
Median (IQR) & \\
Sex, No. (\%) & $205(77.4)$ \\
Male & $60(22.6)$ \\
Female & $150(56.6)$ \\
History of smoke, No. (\%) & $103(38.9)$ \\
History of drink, No. (\%) & $95(35.8)$ \\
Hypertension, No. (\%) & $87(32.8)$ \\
Hyperlipidemia, No. (\%) & $44(16.6)$ \\
Diabetes, No. (\%) & \\
Pathological grade, No. (\%) & $44(16.6)$ \\
G1 & $160(60.4)$ \\
G2 & $61(23.0)$ \\
G3 &
\end{tabular}

NSCLC non-small cell lung carcinoma, SD standard deviation, $L Y N$ lymph node, CEA carcinoembryonic antigen, IQR interquartile range

(63.8\%) and 46 (36.2\%) katanin P60-low patients had tumor size $\leq 5 \mathrm{~cm}$ and $>5 \mathrm{~cm}$, respectively, while 77 (55.8\%) and $61(44.2 \%)$ katanin P60-high patients had tumor size $\leq 5 \mathrm{~cm}$ and $>5 \mathrm{~cm}$, respectively; which showed that katanin P60 expression was not correlated with tumor size $(P=0.186)$ (Fig. $2 b)$. There were 92 (72.4\%) and 35 (27.6\%) katanin P60-low patients with LYN metastasis absent and present, respectively while 80 (58.0\%) and 58 (42.0\%) katanin P60-high patients with LYN metastasis absent and present, respectively; analysis revealed that katanin P60 expression was correlated with LYN metastasis $(P=0.014)$ (Fig. $2 b)$. The number of patients with TNM stage I, II, and III were 49 (38.6\%), 45 (35.4\%), and $33(26.0 \%)$ in katanin P60-low patients and 37 (26.8\%), 45 (32.6\%), and $46(40.6 \%)$ in katanin P60high patients, which indicated that katanin P60 expression was correlated with advanced TNM stage $(P=$ 0.008 ) (Fig. 2d). There were 61 (48.0\%) and 66 (52.0\%) katanin P60-low patients with normal and abnormal 


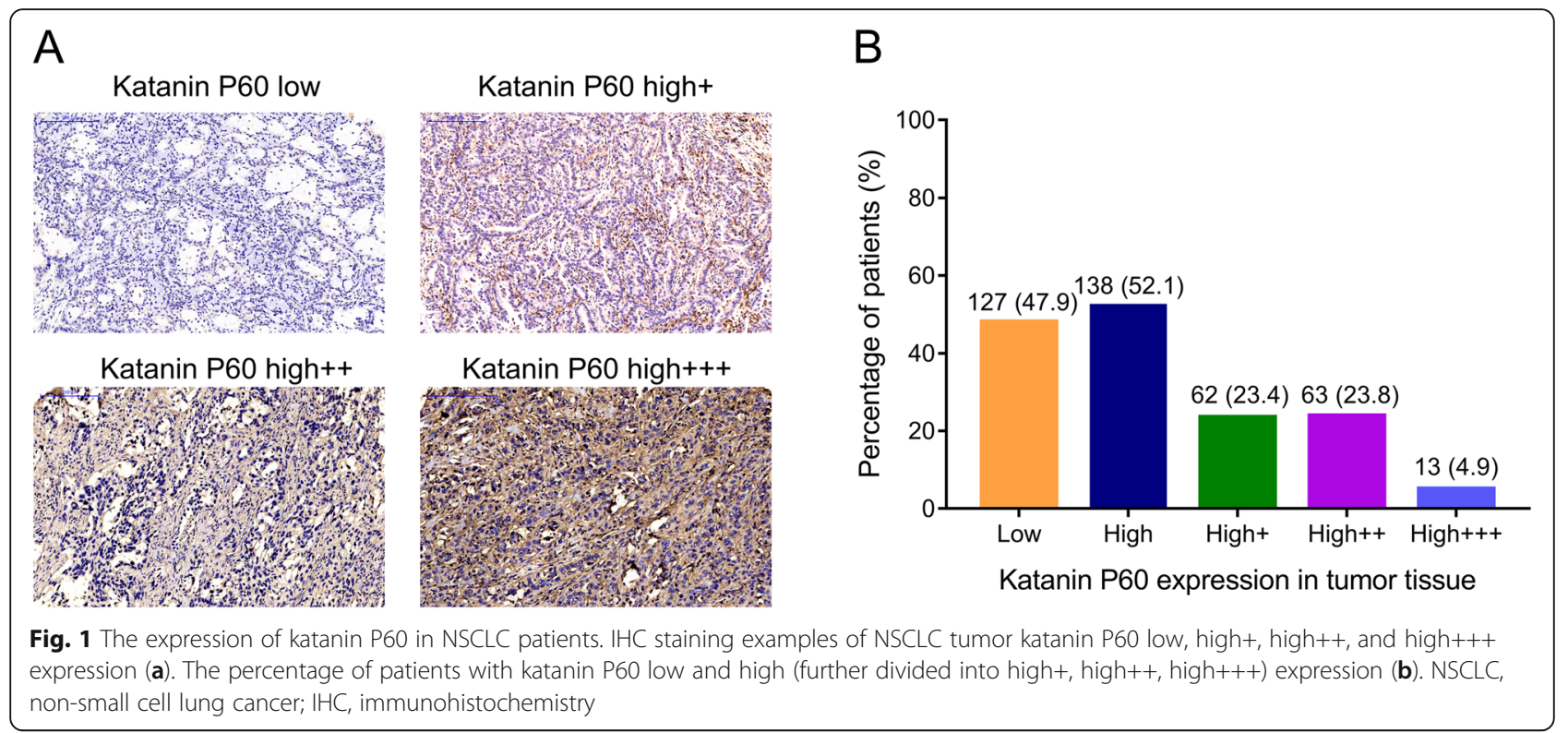

CEA level, respectively while 58 (42.0\%) and 80 (58.0\%) katanin P60-high patients with normal and abnormal CEA level respectively, which showed that katanin P60 expression was not associated with CEA level $(P=$ 0.326) (Fig. 2e). In addition, katanin $P 60$ expression was not correlated with age $(P=0.178)$, sex $(P=0.714)$, history of smoke $(P=0.782)$, history of drink $(P=0.176)$, hypertension $(P=0.246)$, hyperlipidemia $(P=0.856)$, or diabetes $(P=$ 0.490 ) in NSCLC patients (Table 2). For further validation, katanin P60 mRNA expression was detected in 40 fresh tumor samples (Supplementary Figure 1A); then, katanin
P60 mRNA high expression was also shown to be correlated with LYN metastasis $(P=0.038)$ and higher TNM stage $(P<$ 0.001 ) but not with pathological grade, tumor size, or CEA level (all $P>0.05$ ) (Supplementary Figure 1B-1F).

\section{Correlation of katanin P60 expression with DFS in NSCLC patients}

The DFS was shorter in katanin P60-high patients compared with katanin P60-low patients $(P<0.001)$ (Fig. 3a). In addition, patients with katanin $\mathrm{P} 60$ high+++ presented with the lowest DFS, followed by patients with katanin

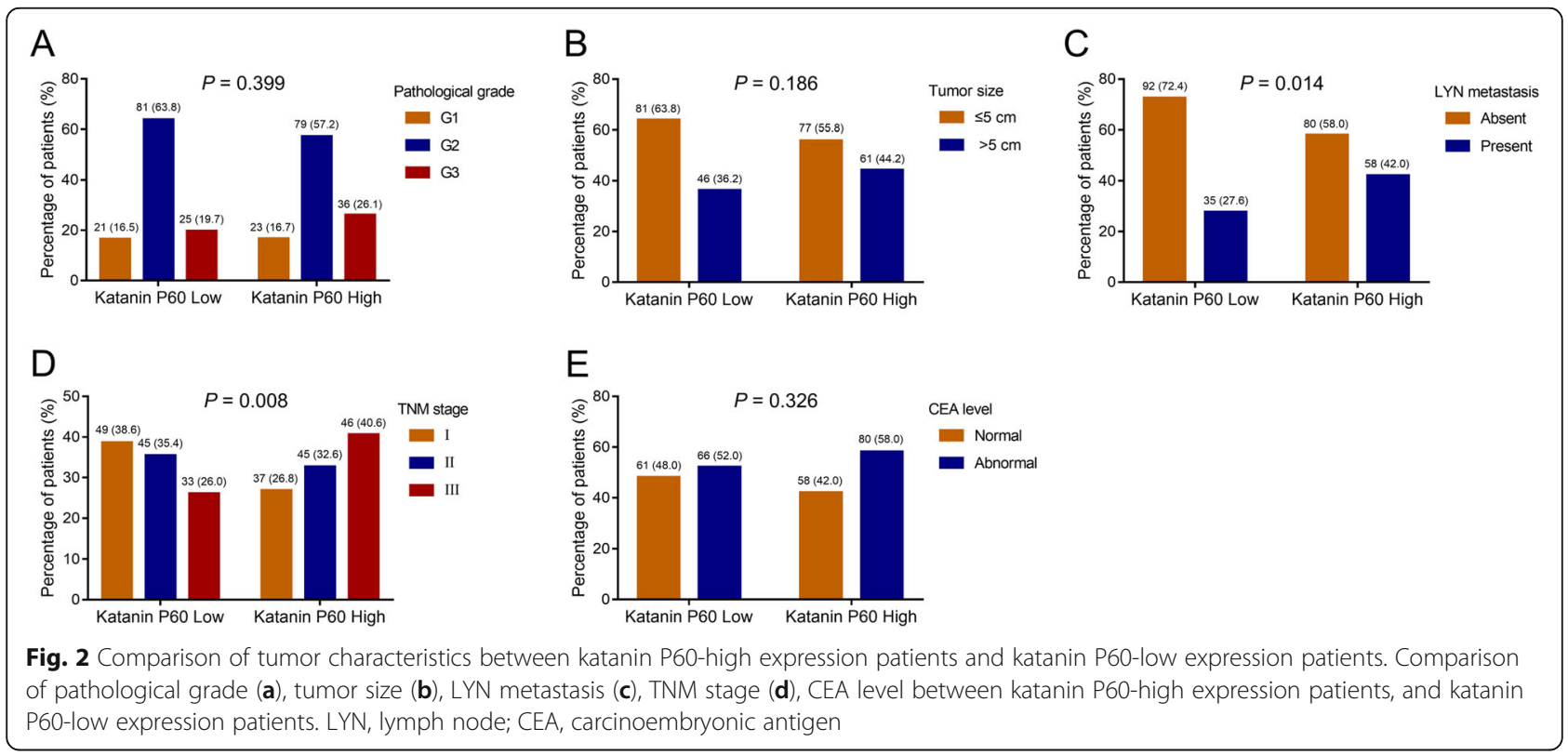


Table 2 Correlation of katanin P60 expression with demographic features and chronic complications

\begin{tabular}{|c|c|c|c|}
\hline \multirow[t]{2}{*}{ Items } & \multicolumn{2}{|c|}{ Katanin P60 expression } & \multirow{2}{*}{$\begin{array}{l}P \\
\text { value }\end{array}$} \\
\hline & $\operatorname{Low}(n=127)$ & High $(n=138)$ & \\
\hline Age, No. (\%) & & & 0.178 \\
\hline$>60.0$ years & $65(51.2)$ & $82(59.4)$ & \\
\hline$\leq 60.0$ years & $62(48.8)$ & $56(40.6)$ & \\
\hline Sex, No. (\%) & & & 0.714 \\
\hline Male & $97(76.4)$ & $108(78.3)$ & \\
\hline Female & $30(23.6)$ & $30(21.7)$ & \\
\hline History of smoke, No. (\%) & & & 0.782 \\
\hline Yes & $73(57.5)$ & $77(55.8)$ & \\
\hline No & $54(42.5)$ & $61(44.2)$ & \\
\hline History of drink, No. (\%) & & & 0.176 \\
\hline Yes & $44(34.6)$ & $59(42.8)$ & \\
\hline No & $83(65.4)$ & $79(57.2)$ & \\
\hline Hypertension, No. (\%) & & & 0.246 \\
\hline Yes & $41(32.3)$ & $54(39.1)$ & \\
\hline No & $86(67.7)$ & $84(60.9)$ & \\
\hline Hyperlipidemia, No. (\%) & & & 0.856 \\
\hline Yes & $41(32.3)$ & $46(33.3)$ & \\
\hline No & $86(67.7)$ & $92(66.7)$ & \\
\hline Diabetes, No. (\%) & & & 0.490 \\
\hline Yes & $19(15.0)$ & $25(18.1)$ & \\
\hline No & $108(85.0)$ & $113(81.9)$ & \\
\hline
\end{tabular}

Comparison was determined by Chi-square test
P60 high++, high+, and patients with katanin P60 low presented with the longest DFS $(P<0.001)$ (Fig. $3 b)$.

\section{Factors affecting DFS in NSCLC patients}

Univariate Cox's proportional hazard regression analysis of DFS displayed that katanin P60-high expression $(P=$ $0.001, \mathrm{HR}=1.607)$, tumor size $(>5.0 \mathrm{~cm})(P=0.018, \mathrm{HR}$ $=1.389)$, LYN metastasis $(P<0.001, \mathrm{HR}=2.565)$, higher TNM stage $(P<0.001, \mathrm{HR}=1.524)$, and abnormal CEA level $(P=0.011, \mathrm{HR}=1.420)$ were correlated with poor DFS in NSCLC patients (Table 3). Forward stepwise multivariate Cox's regression further disclosed that katanin P60-high expression $(P=0.002, \mathrm{HR}=1.527)$, LYN metastasis $(P<0.001, \mathrm{HR}=2.395)$, and abnormal CEA level $(P=0.020, \mathrm{HR}=1.382)$ were independent predictive factors for poor DFS in NSCLC patients.

\section{Correlation of katanin P60 expression with OS in NSCLC patients}

The OS was shorter in katanin P60-high patients compared with katanin P60-low patients $(P=0.003)$ (Fig. 4a). In addition, patients with katanin $\mathrm{P} 60$ high+++ were with the shortest OS, followed by those with katanin P60 high++, high+, and patients with katanin P60 low had the longest $\mathrm{OS}(P=0.002)$ (Fig. 4b).

\section{Factors affecting OS in NSCLC patients}

Univariate Cox's proportional hazard regression analysis of OS displayed that katanin P60-high expression $(P=$ $0.004, \mathrm{HR}=1.567)$, higher pathological grade $(P=0.001$, $\mathrm{HR}=1.508)$, tumor size $(>5.0 \mathrm{~cm})(P=0.008, \mathrm{HR}=$ 1.499), LYN metastasis $(P<0.001, \mathrm{HR}=3.107)$, higher TNM stage $(P<0.001, \mathrm{HR}=1.494)$, and abnormal CEA
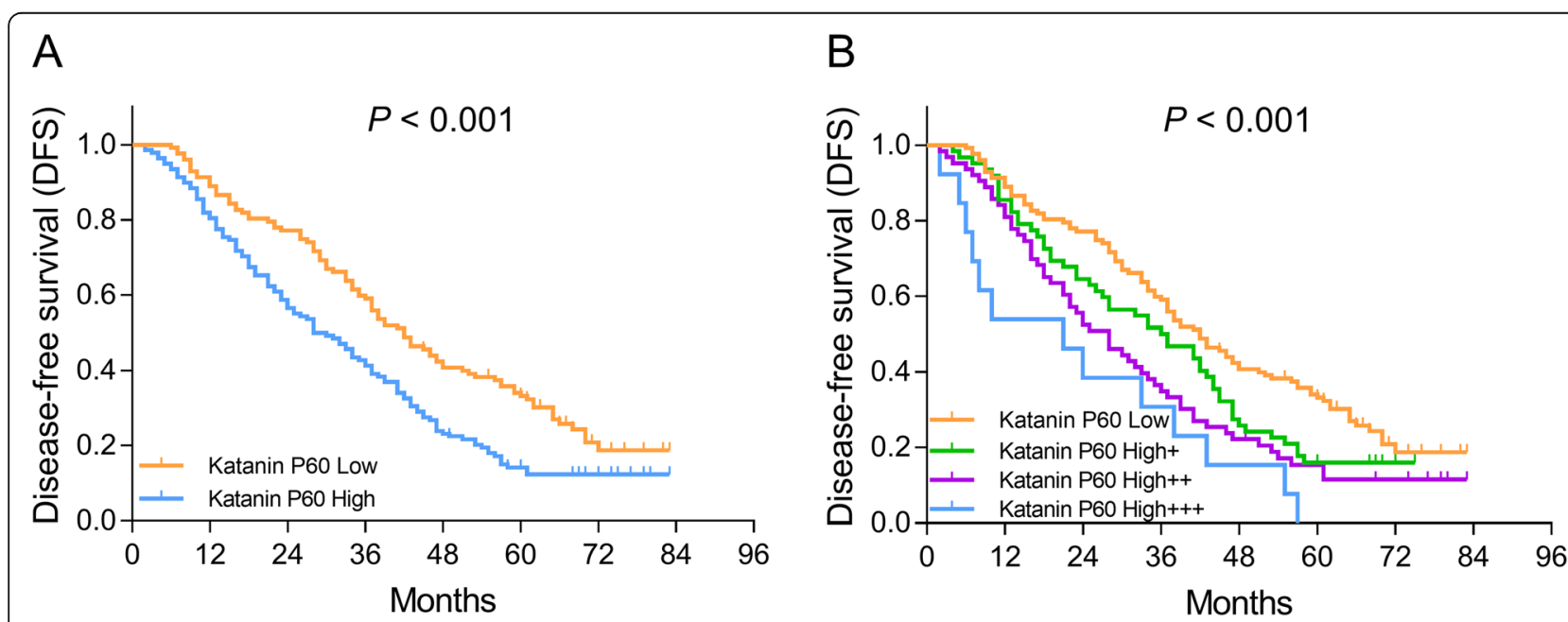

Fig. 3 Comparison of DFS among patients with different katanin P60 expressions. Comparison of DFS between patients with katanin P60-low expression and patients with katanin P60-high expression (a). Comparison of DFS among patients with katanin P60-low expression, patients with katanin P60-high+ expression, patients with katanin P60-high++ expression, and patients with katanin P60-high+++ expression (b). DFS, disease-free survival 
Table 3 Cox's proportional hazard regression analysis of DFS

\begin{tabular}{|c|c|c|c|c|}
\hline \multirow[t]{3}{*}{ Items } & \multicolumn{4}{|c|}{ Cox's regression analysis } \\
\hline & \multirow[t]{2}{*}{$P$ value } & \multirow[t]{2}{*}{$\mathrm{HR}$} & \multicolumn{2}{|l|}{$95 \% \mathrm{Cl}$} \\
\hline & & & Lower & Higher \\
\hline \multicolumn{5}{|l|}{ Univariate Cox's regression } \\
\hline Katanin P60 high & 0.001 & 1.607 & 1.226 & 2.107 \\
\hline Age (> 60.0 years) & 0.158 & 1.216 & 0.927 & 1.596 \\
\hline Male & 0.757 & 1.053 & 0.758 & 1.464 \\
\hline History of smoke & 0.844 & 0.973 & 0.744 & 1.274 \\
\hline History of drink & 0.658 & 1.064 & 0.809 & 1.400 \\
\hline Hypertension & 0.928 & 0.987 & 0.747 & 1.304 \\
\hline Hyperlipidemia & 0.362 & 0.874 & 0.655 & 1.167 \\
\hline Diabetes & 0.126 & 0.740 & 0.503 & 1.088 \\
\hline Higher pathological grade & 0.061 & 1.218 & 0.991 & 1.498 \\
\hline Tumor size $(>5.0 \mathrm{~cm})$ & 0.018 & 1.389 & 1.059 & 1.823 \\
\hline LYN metastasis & $<0.001$ & 2.565 & 1.943 & 3.388 \\
\hline Higher TNM stage & $<0.001$ & 1.524 & 1.288 & 1.804 \\
\hline CEA abnormal (> 5.0 ng/mL) & 0.011 & 1.420 & 1.084 & 1.860 \\
\hline \multicolumn{5}{|c|}{ Forward stepwise multivariate Cox's regression } \\
\hline Katanin P60 high & 0.002 & 1.527 & 1.161 & 2.010 \\
\hline LYN metastasis & $<0.001$ & 2.395 & 1.809 & 3.169 \\
\hline CEA abnormal (> 5.0 ng/mL) & 0.020 & 1.382 & 1.052 & 1.815 \\
\hline
\end{tabular}

DFS disease-free survival, $H R$ hazard ratio, $C I$ confidence interval, $L Y N$ lymph node, CEA carcinoembryonic antigen

$(P=0.001, \mathrm{HR}=1.668)$ were correlated with poor OS (Table 4). Forward stepwise multivariate Cox's regression further disclosed that katanin P60-high expression $(P=$ $0.020, \mathrm{HR}=1.441)$, higher pathological grade $(P=0.009$, $\mathrm{HR}=1.386)$, LYN metastasis $(P<0.001, \mathrm{HR}=2.801)$, and abnormal CEA $(P=0.005, \mathrm{HR}=1.560)$ were independent predictive factors for poor OS in NSCLC patients.

\section{Discussion}

The present study revealed that in NSCLC patients, tumor katanin P60 expression was correlated with LYN metastasis and advanced TNM stage; katanin P60-high expression was an independent predictive factor for poor DFS and OS.

Microtubule plays a vital role in regulating cell cycle, and dysregulated microtubule dynamics is correlated with abnormal cell proliferation, trafficking, signaling, and migration, which are correlated with the development and progression of malignancies [16, 17]. In lung cancer cells, inhibition of microtubule dynamics has been reported to induce $G_{2} / M$ cell cycle arrest [18]. Moreover, microtubule-regulating kinesins, such as KIF18B, are involved in accelerating cell proliferation, migration, and invasion via mediating $\mathrm{AKT} / \mathrm{mTOR}$, and thereby contribute to advanced tumor stage and correlates with unfavorable prognosis in lung adenocarcinoma patients [19]. Hence, microtubule-regulating enzymes may set off a unique and original branch for cancer research.

Katanin is an essential ATPase that degrades microtubule by severing and regulates cell movement. As one of the subunits of katanin heterodimer, katanin $\mathrm{P} 60$ promotes ATPase hydrolysis and depolymerizes microtubule, which contributes to tumor metastasis in several cancers. In cervical cancer, katanin $\mathrm{P} 60$ causes $\mathrm{G}_{2} / \mathrm{M}$ arrest, affects cell mitosis and tumor metastasis [20]. Katanin P60 is highly expressed in breast cancer bone metastasis tissue compared with primary tumor tissue, and overexpression of katanin P60 promotes cell migration but downregulation of katanin P60 suppresses cell migration in breast cancer cells [5]. In addition, katanin
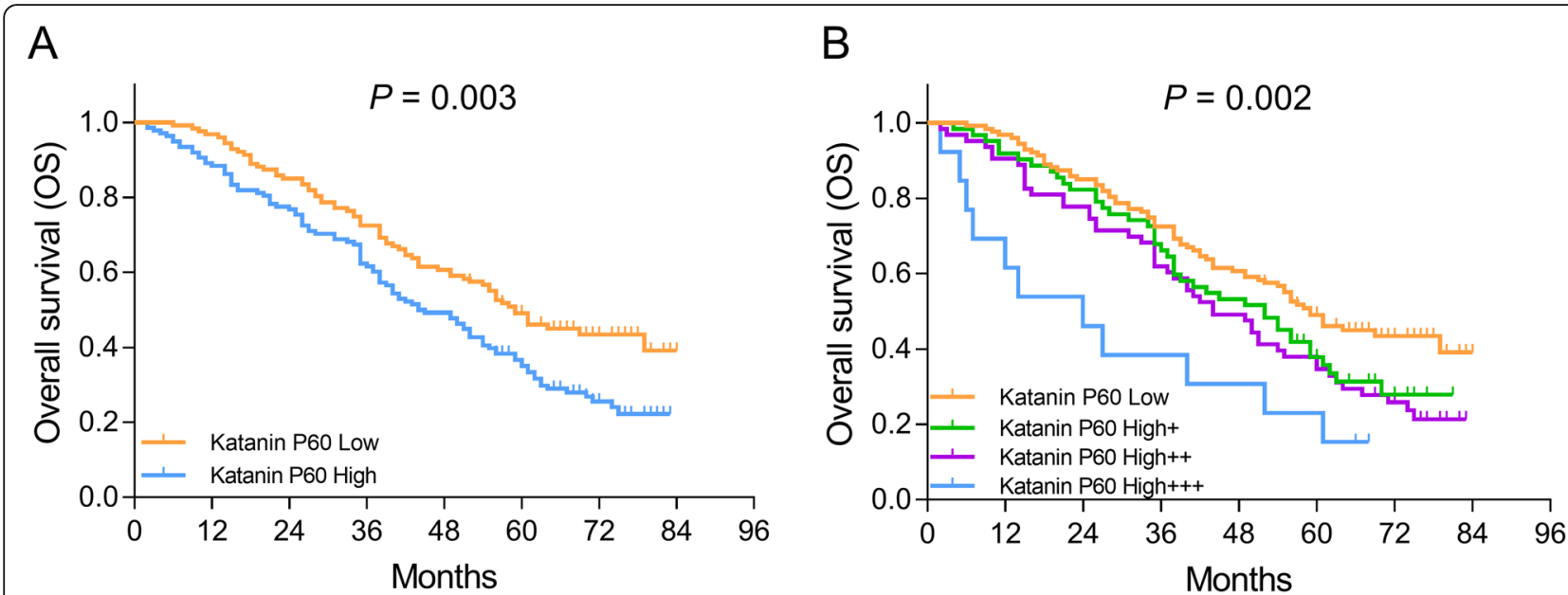

Fig. 4 Comparison of OS among patients with different katanin P60 expressions. Comparison of OS between patients with katanin P60-low expression and patients with katanin P60-high expression (a). Comparison of OS among patients with katanin P60-low expression, patients with katanin P60-high+ expression, patients with katanin P60-high++ expression, and patients with katanin P60-high+++ expression (b). OS, overall survival 
Table 4 Cox's proportional hazard regression analysis of OS

\begin{tabular}{|c|c|c|c|c|}
\hline \multirow[t]{3}{*}{ Items } & \multicolumn{4}{|c|}{ Cox's regression analysis } \\
\hline & \multirow[t]{2}{*}{$P$ value } & \multirow[t]{2}{*}{$\mathrm{HR}$} & \multicolumn{2}{|l|}{$95 \% \mathrm{Cl}$} \\
\hline & & & Lower & Higher \\
\hline \multicolumn{5}{|l|}{ Univariate Cox's regression } \\
\hline Katanin P60 high & 0.004 & 1.567 & 1.155 & 2.126 \\
\hline Age (> 60.0 years) & 0.986 & 0.997 & 0.737 & 1.350 \\
\hline Male & 0.469 & 0.877 & 0.616 & 1.250 \\
\hline History of smoke & 0.641 & 1.075 & 0.794 & 1.455 \\
\hline History of drink & 0.646 & 1.074 & 0.791 & 1.460 \\
\hline Hypertension & 0.619 & 0.923 & 0.674 & 1.265 \\
\hline Hyperlipidemia & 0.496 & 0.893 & 0.646 & 1.236 \\
\hline Diabetes & 0.291 & 0.795 & 0.520 & 1.216 \\
\hline Higher pathological grade & 0.001 & 1.508 & 1.196 & 1.901 \\
\hline Tumor size $(>5.0 \mathrm{~cm})$ & 0.008 & 1.499 & 1.109 & 2.026 \\
\hline LYN metastasis & $<0.001$ & 3.107 & 2.287 & 4.221 \\
\hline Higher TNM stage & $<0.001$ & 1.494 & 1.238 & 1.804 \\
\hline CEA abnormal (> 5.0 ng/mL) & 0.001 & 1.668 & 1.225 & 2.270 \\
\hline \multicolumn{5}{|c|}{ Forward stepwise multivariate Cox's regression } \\
\hline Katanin P60 high & 0.020 & 1.441 & 1.060 & 1.959 \\
\hline Higher pathological grade & 0.009 & 1.386 & 1.084 & 1.774 \\
\hline LYN metastasis & $<0.001$ & 2.801 & 2.057 & 3.814 \\
\hline CEA abnormal (> 5.0 ng/mL) & 0.005 & 1.560 & 1.144 & 2.126 \\
\hline
\end{tabular}

OS overall survival, $H R$ hazard ratio, $C l$ confidence interval, $L Y N$ lymph node, CEA carcinoembryonic antigen

P60-high expression is reported to be correlated with LYN metastasis and poor OS in breast cancer patients [11]. In colon cancer cells, katanin P60, activated by tumor suppressor protein p53, is vital in maintaining cell survival, apoptosis, and differentiation [21]. As for prostate cancer, overexpression of katanin P60 inhibits cell proliferation but enhances cell migration, which suggests that katanin P60 accelerates prostate cancer cell metastasis [10]. The above studies illuminate the role of katanin P60 in facilitating cancer cell migration in cancers. However, limited information about the characteristics of katanin P60 in NSCLC is currently available, but one previous in vitro study mentions that katanin P60 is targeted by purine-type compound $5 \mathrm{a}$ that induces microtubule fragmentation and cancer cell death in lung cancer [12]. Thus, we assessed the expression and the correlation of katanin P60 with clinical features in NSCL $\mathrm{C}$ patients. It was observed that both katanin $\mathrm{P} 60$ protein and mRNA expressions were correlated with LYN metastasis and advanced TNM stage, but not pathological grade, tumor size, and CEA level in NSCLC patients. Although lacking detailed mechanisms of katanin P60 in NSCLC, the correlation of katanin P60 with LYN metastasis could be explained as follows: katanin P60 activation might stimulate cell motility and cell division via regulating microtubule dynamics and increase cell migration, thereby contributing to tumor metastasis in NSCLC [12].

Nevertheless, considering that katanin P60 is associated with poor OS in breast cancer patients, we evaluated the correlation of katanin P60 with survival profiles in NSCLC patients as well and found that katanin P60 was associated with poor DFS and OS, and further analysis illustrated that katanin P60 was an independent predictive factor for unfavorable DFS and OS in NSCLC patients [11].The possible reasons were as follows: (1) Upregulated katanin P60 might increase microtubule dynamics, accelerate cell cycle, and increase cell viability and cell migration, which promoted tumor metastasis in NSCLC and consequently led to unfavorable survival. (2) As observed in this study, katanin P60 was associated with LYN metastasis and advanced TNM stage, which were known as risk factors for poor prognosis in NSCLC patients. (3) As the cell proliferation was upregulated by katanin P60, the point mutations might be amplificated by increased number of genetic material duplication, which elevated the expression of tumor promotive genes such as TP53, MYC, and $M E T$, and these genetic mutations might contribute to the development of chemoresistance and reduce the treatment response as well as survival outcomes in NSCLC patients [22]. Our findings were consistent with the previous study that katanin P80 correlates with larger tumor size, LYN metastasis, and advanced TNM stage and predicts poor survival in NSCLC patients [9]. Furthermore, there was a consistency between katanin P60 and katanin P80 expression in NSCLC, which was shown by our additional analysis (Supplementary Table 1, Supplementary Figure 2).

To our knowledge, the present study was the first that investigated katanin P60 in NSCLC progression and prognosis in clinical settings. However, despite the clinical implication, the mechanism of katanin P60 in the pathogenesis of NSCLC was not studied, which could be further explored to support our findings. Besides, only surgical NSCLC patients (TNM stage I-IIIA) were included in this study; therefore, our results might not be applicable for all stage NSCLC patients especially the advanced NSCLC patients.

\section{Conclusion}

In conclusion, we present the initial experience that katanin P60 is sufficiently expressed and correlated with LYN metastasis and unfavorable survival profiles in NSCLC patients.

\section{Supplementary information}

Supplementary information accompanies this paper at https://doi.org/10. 1186/s12957-020-01939-z.

Additional file 1:. Figure S1. Comparison of tumor characteristics between katanin P60 high expression patients and katanin P60 low 
expression patients: validation by mRNA expression. MRNA expression of katanin P60 in 40 samples (A). Comparison of pathological grade (B), tumor size (C), LYN metastasis (D), TNM stage (E), CEA level (F) between katanin P60 high expression patients and katanin P60 low expression patients. LYN, lymph node; CEA, carcinoembryonic antigen.

Additional file 2:. Table S1. Correlation of Katanin P60 with Katanin P80 expression in NSCLC tumor $\mathrm{t}$

Additional file 3:. Figure S2. Consistent and inconsistent expression of katanin P60 and ka0 in NSCLC tissues. NSCLC, Non-small cell lung cancer.

\section{Abbreviations}

NSCLC: Non-small cell lung cancer; OS: Overall survival; IHC: Immunohistochemical; LYN: Lymph node; CEA: Carcinoembryonic antigen; DFS: Disease-free survival; SD: Standard deviation; IQR: Interquartile; K-M: Kaplan-Meier

\section{Acknowledgements}

Not applicable.

\section{Authors' contributions}

Conception and design: X Zhu. Administrative support: X Zhu. Provision of study materials or patients: L Wang and J Tantai. Collection and assembly of data: L Wang. Data analysis and interpretation: J Tantai. Manuscript writing: All authors. Final approval of manuscript: All authors.

\section{Funding}

This study was supported by Shanghai Municipal Health and Family Planning Commission (201640213), Key Research and Development Project of Jiangsu Province (BE2017671), Science and Education to Revitalize Health Engineering Medical Key Talent Project of Jiangsu Province (ZDRCA2016038) and Clinical Ancillary Department Capacity Building Project of Shanghai Shenkang Hospital Development Center (SHDC22015020).

\section{Availability of data and materials}

The datasets used and/or analyzed during the current study are available from the corresponding author upon reasonable request.

\section{Ethics approval and consent to participate}

Approval for this study was obtained from Ethics Committee of The First Affiliated Hospital of Soochow University. The written informed consents were acquired from the patients or their family members.

\section{Consent for publication}

Not applicable

\section{Competing interests}

The authors declare that they have no competing interests.

\section{Author details}

'Department of Interventional Radiology, The First Affiliated Hospital of Soochow University, 899 Pinghai Road, Suzhou 215006, China. ${ }^{2}$ Department of Ultrasound, Shanghai Chest Hospital, Shanghai Jiao Tong University, Shanghai, China. ${ }^{3}$ Department of Thoracic Surgery, Shanghai Chest Hospital, Shanghai Jiao Tong University, Shanghai, China.

Received: 3 March 2020 Accepted: 29 June 2020

Published online: 06 July 2020

\section{References}

1. Arbour KC, Riely GJ. Systemic therapy for locally advanced and metastatic non-small cell lung cancer: a review. JAMA. 2019;322:764-74.

2. Herbst RS, Morgensztern D, Boshoff $C$. The biology and management of non-small cell lung cancer. Nature. 2018:553:446-54.

3. Smolle E, Leithner K, Olschewski H. Oncogene addiction and tumor mutational burden in non-small-cell lung cancer: clinical significance and limitations. Thorac Cancer. 2019

4. Roll-Mecak A, McNally FJ. Microtubule-severing enzymes. Curr Opin Cell Biol. 2010;22:96-103.

5. Fu W, Wu H, Cheng Z, Huang S, Rao H. The role of katanin p60 in breast cancer bone metastasis. Oncol Lett. 2018;15:4963-9.
6. Chen K, Ye Y, Ji Z, Tan M, Li S, Zhang J, Guo G, Lin H. Katanin p60 promotes neurite growth and collateral formation in the hippocampus. Int J Clin Exp Med. 2014;7:2463-70

7. Whitehead $\mathrm{E}$, Heald R, Wilbur JD. N-terminal phosphorylation of p60 katanin directly regulates microtubule severing. J Mol Biol. 2013;425:214-21.

8. Ahmad FJ, Yu W, McNally FJ, Baas PW. An essential role for katanin in severing microtubules in the neuron. J Cell Biol. 1999;145:305-15.

9. Ye Q, Zhang M, Yin Y: Katanin P80 correlates with larger tumor size, lymph node metastasis, and advanced TNM stage and predicts poor prognosis in non-small-cell lung cancer patients. J Clin Lab Anal 2020:e23141.

10. Ye X, Lee YC, Choueiri M, Chu K, Huang CF, Tsai WW, Kobayashi R, Logothetis CJ, Yu-Lee LY, Lin SH. Aberrant expression of katanin p60 in prostate cancer bone metastasis. Prostate. 2012;72:291-300.

11. Zuo L, Ying JS, Zhang FC, Xu YC. Tumor tissue katanin P60 expression correlates with lymph node metastasis and worse prognosis in patients with breast cancer: a cohort study. Cancer Biomark. 2018;21:425-32.

12. Kuo TC, Li LW, Pan SH, Fang JM, Liu JH, Cheng TJ, Wang CJ, Hung PF, Chen $H Y$, Hong TM, et al. Purine-type compounds induce microtubule fragmentation and lung cancer cell death through interaction with katanin. J Med Chem. 2016:59:8521-34.

13. Wei L, Liu Y, Ma Y, Ding C, Zhang H, Lu Z, Gu Z, Zhu C. C-X-C chemokine receptor 2 correlates with unfavorable prognosis and facilitates malignant cell activities via activating JAK2/STAT3 pathway in non-small cell lung cancer. Cell Cycle. 2019;18:3456-71.

14. Tian Y, Zhao K, Yuan L, Li J, Feng S, Feng Y, Fang Z, Li H, Deng R. EIF3B correlates with advanced disease stages and poor prognosis, and it promotes proliferation and inhibits apoptosis in non-small cell lung cancer. Cancer Biomark. 2018;23:291-300.

15. Fu H, Jin C, Zhu Q, Liu T, Ke B, Li A, Zhang T. Dysregulated expressions of PTEN NF-kappaB, WWP2, p53 and c-Myc in different subtypes of B cell lymphoma and reactive follicular hyperplasia. Am J Trans/ Res. 2019;11:1092-101.

16. Otto T, Sicinski P. Cell cycle proteins as promising targets in cancer therapy. Nat Rev Cancer. 2017:17:93-115.

17. Dumontet C, Jordan MA. Microtubule-binding agents: a dynamic field of cancer therapeutics. Nat Rev Drug Discov. 2010;9:790-803.

18. Ho ST, Lin CC, Tung YT, Wu JH. Molecular mechanisms underlying yateininduced cell-cycle arrest and microtubule destabilization in human lung adenocarcinoma cells. Cancers (Basel). 2019;11.

19. Ji Z, Pan X, Shang Y, Ni DT, Wu FL. KIF18B as a regulator in microtubule movement accelerates tumor progression and triggers poor outcome in lung adenocarcinoma. Tissue Cell. 2019;61:44-50.

20. Maddika S, Chen J. Protein kinase DYRK2 is a scaffold that facilitates assembly of an E3 ligase. Nat Cell Biol. 2009;11:409-19.

21. Kirimtay K, Selcuk E, Kelle D, Erman B, Karabay A. p53 regulates katanin-p60 promoter in HCT 116 cells. Gene. 2020;727:144241.

22. Petrek H, Yu AM. MicroRNAs in non-small cell lung cancer: gene regulation, impact on cancer cellular processes, and therapeutic potential. Pharmacol Res Perspect. 2019;7:e00528.

\section{Publisher's Note}

Springer Nature remains neutral with regard to jurisdictional claims in published maps and institutional affiliations.

Ready to submit your research? Choose BMC and benefit from:

- fast, convenient online submission

- thorough peer review by experienced researchers in your field

- rapid publication on acceptance

- support for research data, including large and complex data types

- gold Open Access which fosters wider collaboration and increased citations

- maximum visibility for your research: over $100 \mathrm{M}$ website views per year

At BMC, research is always in progress.

Learn more biomedcentral.com/submission 